\title{
Clinical usefulness of a single-use splinting tube for poor endoscope operability in deep colonic endoscopic submucosal dissection
}

Authors

Institutions
Naoki Asayama', Shiro Oka', Shinji Tanaka', Kyoku Sumimoto², Daiki Hirano², Yuzuru Tamaru², Yuki Ninomiya², Kenjiro Shigita ${ }^{2}$, Nana Hayashi' ${ }^{1}$, Soki Nishiyama ${ }^{2}$, Kazuaki Chayama ${ }^{2}$

${ }^{1}$ Departments of Endoscopy, Hiroshima University Hospital, Hiroshima, Japan

${ }^{2}$ Department of Gastroenterology and Metabolism, Hiroshima University Hospital, Hiroshima, Japan submitted 26. January 2016 accepted after revision 7. March 2016

\section{Bibliography}

Dol http://dx.doi.org/

10.1055/s-0042-105434

Published online: 15.4.2016

Endoscopy International Open 2016; 04: E614-E617

(c) Georg Thieme Verlag KG Stuttgart · New York

E-ISSN 2196-9736

\section{Corresponding author}

\section{Shiro Oka}

Department of Endoscopy

Hiroshima University

1-2-3 Kasumi, Minami-ku

Hiroshima 734-8551

Japan

Fax: +81-82-257-5939

oka4683@hiroshima-u.ac.jp
Background and study aims: Poor endoscope operability remains a significant challenge during colorectal endoscopic submucosal dissection (ESD). We retrospectively evaluated the experience and clinical usefulness of a new single-use splinting tube in deep colonic ESD in the setting of poor scope operability.

Patients and methods: Among 691 patients with colorectal tumors treated with ESD at Hiroshima University Hospital between November 2009 and July 2015, we analyzed 20 consecutive patients who underwent deep colonic ESD using a singleuse splinting tube because of poor scope operability. Poor operability was defined as paradoxical

\section{Introduction}

With the development of various new tools and peripheral devices and the accumulation of experience and expertise, colorectal endoscopic submucosal dissection (ESD) is gradually gaining widespread acceptance in Japan [1 -3]. Technical difficulties associated with colorectal ESD have been significantly reduced, and ESD is gaining popularity among experienced endoscopists [4-6]. However, poor endoscope operability in situations when there is paradoxical movement of the endoscope, poor control with adhesions, and lesion motion with heartbeat or breathing can result in failure to achieve en bloc resection or in perforation [7-9]. We also previously reported that poor scope operability during ESD was an independent significant predictor of incomplete resections and perforation [8]. A new splinting tube with a balloon (ST-CB1, Olympus) has been designed for use with PCF-Q260AZI (Olympus). This instrument is used for colonoscopy and deep colonic ESD. Here, we evaluated the clinical usefulness of the single-use splinting tube for poor scope operability in deep colonic ESD. movement of the endoscope, poor control with adhesions, and lesion motion with heartbeat or breathing. Technical and clinical success rates and adverse events were assessed.

Results: Paradoxical movement and poor control with adhesions were improved in all cases using the single-use splinting tube. The en bloc resection rate was 95\% (19/20) and histological en bloc resection rate was $100 \%$ (20/20). There were no complications related to use of the splinting tube.

Conclusions: Use of a single-use splinting tube helped to overcome poor scope operability in deep colonic ESD.

\section{Patients and methods \\ $\nabla$}

\section{Patients}

Among 691 patients with colorectal tumors treated by ESD at Hiroshima University Hospital between November 2009 and July 2015, we analyzed 20 consecutive patients who underwent deep colonic ESD using a single-use splinting tube because of poor scope operability. Poor scope operability was defined as paradoxical movement of the endoscope, poor control with adhesions, and lesion motion with heartbeat or breathing and was classified as good or poor, as described previously [8]. "Paradoxical movement" was defined as retraction of the tip of the colonoscope because the axial force exerted by the endoscopist was not translated to forward motion of the tip of the colonoscope as a result of looping and accumulation of air in the abdomen. "Poor control with adhesion" was defined as unsmooth movement of the colonoscope during ESD, which was caused by adhesions that developed after prior abdominal or pelvic surgery. "Lesion motion with heartbeat or breathing" was defined as troublesome movement of the endoscopic view that was synchronous with the patient's heartbeat or breathing. 

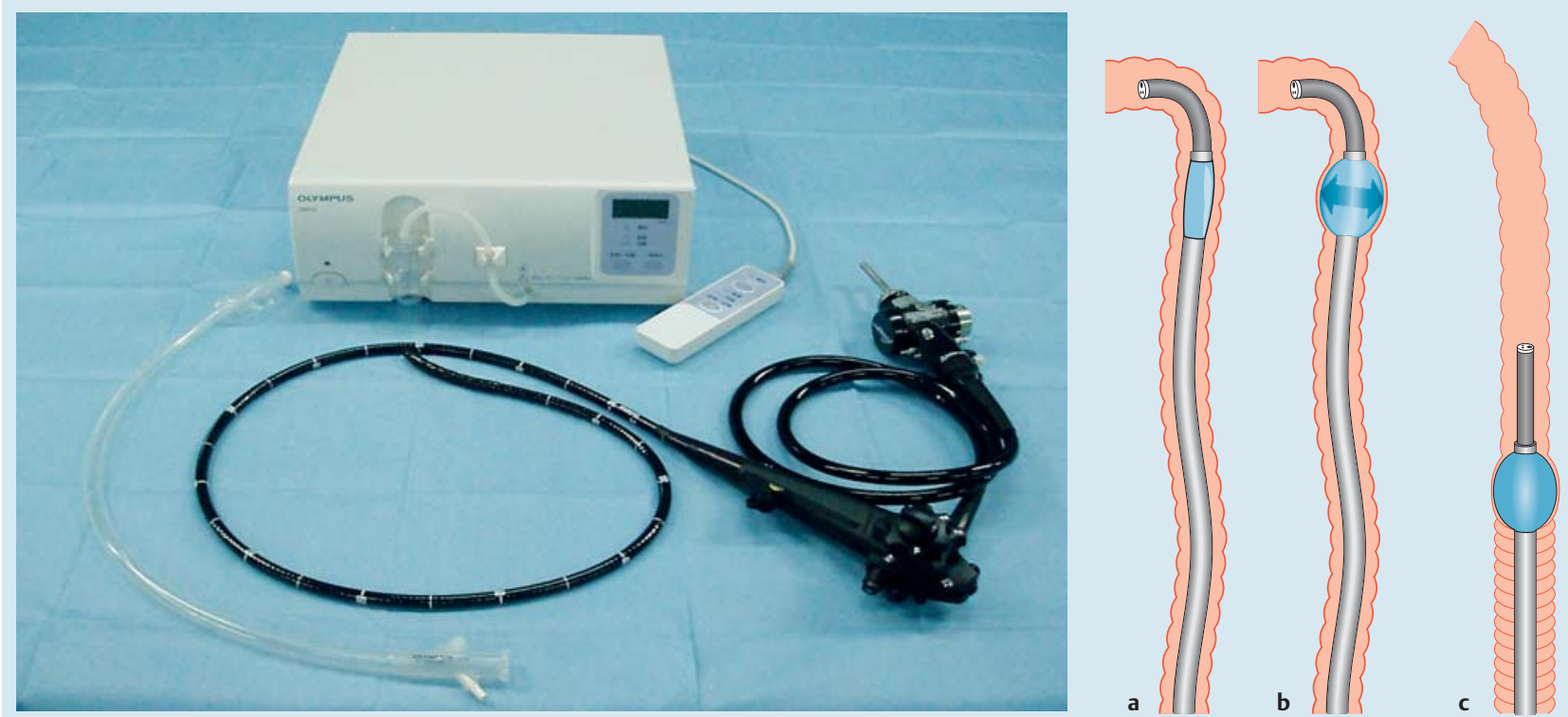

Fig. 1 Single-use splinting tube (ST-CB1). The single-balloon enteroscope system consists of a scope, a single-use splinting tube, and a balloon control unit. Insertion procedure. a Insert the scope, and angulate it to hold the gut and deflate the balloon. $\mathbf{b}$ Advance the sliding tube and inflate the balloon. $\mathbf{c}$ Withdraw both the scope and sliding tube while releasing the angulation, then withdraw both the scope and sliding tube to shorten the intestine. Single-use splinting tube (ST-CB1). a Balloon overtube with a 16.2-mm outer diameter and 13.8-mm inner diameter. The entire length is $770 \mathrm{~mm}$. $\mathbf{b}$ Pre-loading the overtube over the colonoscope.

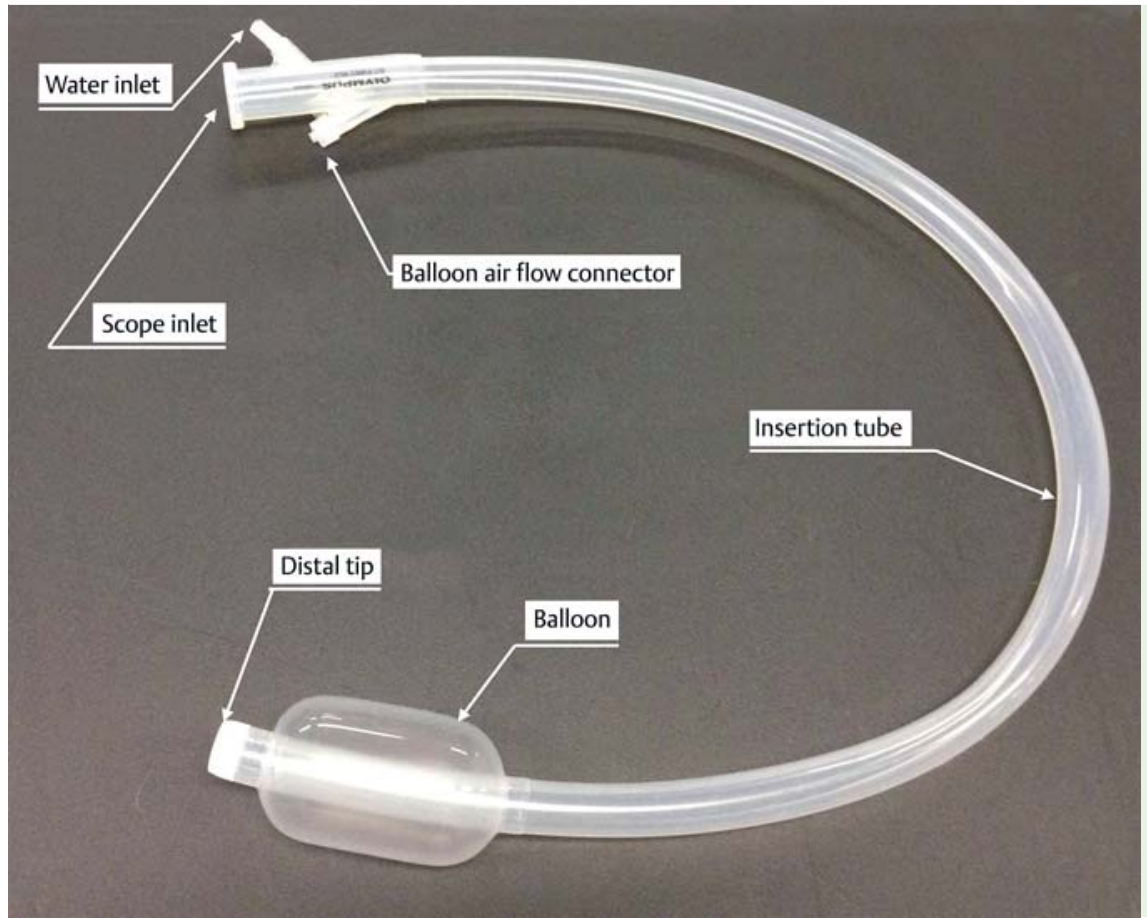

Fig. 2 Single-use splinting tube (ST-CB1). Balloon overtube with a $16.2-\mathrm{mm}$ outer diameter and $13.8-\mathrm{mm}$ inner diameter. The entire length is $770 \mathrm{~mm}$

To determine whether ESD was indicated, all participants had undergone diagnostic colonoscopy using a high-resolution video endoscope with magnification capability (CF-H260AZI, HQ290I, HQ 290 ZI or PCF-Q260AZI; Olympus, Tokyo, Japan). At that time, endoscope operability was also assessed during diagnostic colonoscopy. During ESD, the evaluation of poor scope operability was made subjectively by the operator. All patients had been informed about the risks and benefits of colorectal ESD and provided written informed consent for the procedure. The study protocol was approved by the Institutional Review Board of Hiroshima University Hospital.
Instruments used with the single-use splinting tube Balloon overtube-guided deep colonic ESD was performed with a colonoscope (PCF-Q260AZI; outer diameter of $11.7 \mathrm{~mm}$ or PCFQ260JI; outer diameter of $10.5 \mathrm{~mm}$; Olympus, Tokyo, Japan), a splinting tube with a balloon (ST-CB1, Olympus; outer diameter $43 \mathrm{~mm}$, length $73 \mathrm{~mm}$ ), and a balloon control unit (OBCU, Olympus, Tokyo, Japan) ( $\bullet$ Fig. 1, 2).

This single-use splinting tube (ST-CB1; total length $770 \mathrm{~mm}$, working length $690 \mathrm{~mm}$, outer diameter $16.2 \mathrm{~mm}$, inner diameter $13.8 \mathrm{~mm}$ ) was placed into the colonoscope before insertion. We usually use a standard tip hood (Olympus). A bell-shaped, small- 
caliber tip, transparent tip hood (ST hood, FUJIFILM, Omiya, Japan) was used in cases of severe fibrosis to make it easier to enter the submucosal layer. The procedural processes and the tool set used within the balloon overtube-guided procedure were the same for the deep colonic ESD procedure performed without the splinting tube. Before performing ESD, we place a sheet with excellent water absorbability under the patient because body fluids flow backward from the gap between the splinting tube and the colonoscope. The overtube does not have a valve but air leakage cannot occur easily during ESD. We employed the retroflexion approach when performing deep colonic ESD using the overtube if the approach enabled better manipulation and visualization. We used retroflexion in 10 cases (50\%). The balloon was controlled by the balloon controller, which inflates the balloon with air until the pressure reaches $5.4 \mathrm{kPa}$.

\section{Procedures for colorectal ESD}

The indications for colorectal ESD were based on the criteria proposed by the Colorectal ESD Standardization Implementation Working Group [10]. The procedures were performed by two endoscopic specialists (S.T. and S. O.) as previous reported [8].

The inner surface of the splinting tube was wetted with water, and the tube was fitted onto the colonoscope before intubation. The tube was advanced with the balloon deflated. The colonoscope was moved forward to the descending colon.

The splinting tube was passed along the colonoscope while pulling the scope to the anal side to keep it taut, and the balloon was inflated to fix the tube to the intestinal wall. Next, the colonoscope was inserted into the deep part of the intestine along the tube, while pulling the tube to the anal side to keep it from bending. The splinting tube with the deflated balloon was then moved forward along with the colonoscope. This process was repeated. The colonoscope was controlled by the operator, and the assistant operated the splinting tube and balloon control unit (๑ Fig. 1 and $\odot$ Fig. 2 ).

\section{Outcomes}

We examined demographic data and clinical characteristics (tumor location, size, morphological type, and histology) and evaluated the following clinical outcomes of deep colonic ESD: scope operability, resection rate, horizontal/vertical margin, procedure time, degree of submucosal fibrosis, and adverse events. Severe fibrosis was defined as reported previously [11].

\section{Results}

$\nabla$

The clinical characteristics of patients who underwent deep colonic ESD for colorectal cancer (13 men, 7 women) are shown in $\odot$ Table 1. The mean ( \pm standard deviation [SD]) age of the patients was $68.9 \pm 8.5$ years. The tumor was located in the ascending colon in 9 cases, cecum in 6 cases, and transverse colon in 5 cases. The mean lesion size was $41 \pm 11.3 \mathrm{~mm}$ (range, $20-70 \mathrm{~mm}$ ); 9 cases were laterally spreading tumor-granular type (LST-G) and 11 cases were laterally spreading tumornon-granular type (LST-NG). The most frequent histologic type of the resected lesion was adenoma (9 cases, $45 \%$ ) while the second most common histologic type was Tis carcinoma ( 7 cases, $35 \%)$. Four $(20 \%)$ cases of T1 carcinoma were noted (৫ Table 1 ).

A summary of resectability and other outcomes is shown in - Table2. There were no complications during or after the pro-

\begin{tabular}{|c|c|}
\hline Age (years), mean (range) & $68.9 \pm 8.5(52-84)$ \\
\hline $\operatorname{Sex}(M / F), n(\%)$ & $13(65) / 7(35)$ \\
\hline Tumor size (mm), mean (range) & $41.0 \pm 11.3(20-70)$ \\
\hline \multicolumn{2}{|l|}{ Tumor location, n (\%) } \\
\hline Cecum & $6(30)$ \\
\hline Ascending colon & $9(45)$ \\
\hline Transverse colon & $5(25)$ \\
\hline \multicolumn{2}{|l|}{ Gross type, n (\%) } \\
\hline LST-G & $9(45)$ \\
\hline LST-NG & $11(55)$ \\
\hline \multicolumn{2}{|l|}{ Histology, n (\%) } \\
\hline Adenoma & $9(45)$ \\
\hline \multicolumn{2}{|l|}{ Carcinoma } \\
\hline Tis & $7(35)$ \\
\hline $\mathrm{T} 1$ & $4(20)$ \\
\hline
\end{tabular}

LST-G, laterally spreading tumor-granular type; LST-NG, laterally spreading tumornon-granular type

Table 2 Outcomes of deep colonic endoscopic submucosal dissection.

\begin{tabular}{|c|c|}
\hline \multicolumn{2}{|l|}{ Scope operability during ESD (using ST-CB1) } \\
\hline Good & $11(55)$ \\
\hline Poor & $9(45)$ \\
\hline Paradoxical movement, n (\%) & $0(0)$ \\
\hline Poor control with adhesions, $\mathrm{n}(\%)$ & $0(0)$ \\
\hline Lesion movement with heartbeat or breathing, $\mathrm{n}(\%)$ & $9(0)$ \\
\hline \multicolumn{2}{|l|}{ Resection } \\
\hline En bloc resection, $\mathrm{n}(\%)$ & $19(95)$ \\
\hline Histological en block resection, n (\%) & $20(100)$ \\
\hline Procedure time (min), mean (range) & $141(30-330)$ \\
\hline \multicolumn{2}{|l|}{ Degree of submucosal fibrosis, $\mathrm{n}(\%)$} \\
\hline Mild & $9(45)$ \\
\hline Severe & $11(55)$ \\
\hline \multicolumn{2}{|l|}{ Complication } \\
\hline Delayed bleeding, n (\%) & $0(0)$ \\
\hline Perforation, n (\%) & $1(5)$ \\
\hline
\end{tabular}

cedure. Endoscope operability was good in 11 cases $(55 \%)$ and was poor in 9 (45\%), even when the single-use splinting tube was used. In all 9 cases, the reason for poor operability was lesion motion with the heartbeat or breathing, while paradoxical movement and poor control with adhesions were improved.

The overall en bloc resection rate was 95\% (19/20) and the histological en bloc resection rate was $100 \%(20 / 20)$. In one case, endoscopic operability of a $35-\mathrm{mm}$, laterally spreading cecal lesion that moved with the heartbeat, breathing, or intestinal peristalsis did not improve even when the SBT-CB1 tube was used, resulting in piecemeal resection. Pathologic examination revealed that the carcinomatous portion of the lesion had been resected completely.

The mean operation time was $141 \pm 72.4 \mathrm{~min}$. Severe fibrosis was present in 11 cases. Perforation occurred in 1 patient $(5 \%)$, who recovered with conservative therapy without surgical intervention. No postoperative bleeding or delayed perforation occurred in this series.

\section{Discussion}

Poor endoscope operability remains a significant challenge during colorectal ESD even in the hands of a skilled endoscopist. In this study, the overall en block resection rate and perforation 
rate were $95 \%$ and $5 \%$, respectively. The use of a new sliding tube with a balloon served as an anchor on the colon wall, providing optimal traction for more stabilized access to the lesion. It enabled us to perform deep colonic ESD successfully in difficult cases with poor scope operability. Paradoxical movement and poor control with adhesions were improved in all cases. However, improvement was not seen in all cases with poor scope operability with the use of single-use splinting tube because, in some cases, movement of the lesion with the heartbeat or breathing could not be overcome even with the use of the new splinting tube with a balloon.

Recently, double-balloon colonoscopy was shown to have a high rate of complete colon evaluation in patients whose colon evaluation was incomplete with conventional colonoscopy [12-14]. Ohya et al. [15] reported their experience with using balloon overtube-guided colorectal ESD. They made a balloon overtube that could improve access to the lesion and facilitate scope manipulation in colorectal ESD. However, there were some limitations in using a water jet scope specially designed for colorectal ESD or other traction devices due to the smaller diameter of the balloon. The main features of the new splinting tube are the following: splinting tube with inflatable balloon that supports the position of the endoscope within the colon; suitability for complex therapeutic procedures especially for lesions that are in proximity to flexures; hypoallergenic and latex-free; and hydrophilic-coated silicone that enables smooth passage over the colonoscope. This instrument enabled us to use the colonoscope and to perform deep colonic ESD more easily. As the splinting tube with a balloon system does not have a scope balloon, the scope can be withdrawn and inserted while holding the splinting tube in the gut and attaching the tip hood to the tip of the endoscope. The new splinting tube with a balloon has a tab at the proximal end, making the tube much easier to hold than the overtube used in double-balloon endoscopy.

This study has some limitations. First, it was retrospective cohort study conducted at a single institution. Second, it might be affected by selection bias because it was not randomized. Third, the evaluation of poor scope operability was made subjectively during ESD because the investigated parameters are difficult to evaluate objectively. Large-scale multicenter investigations are needed to evaluate the utility of the splinting tube with a balloon.

\section{Conclusions}

$\nabla$

Use of the splinting tube with a balloon may be useful for improving the complete en bloc resection rate and safety in the setting of poor scope operability in deep colonic ESD.

\section{Competing interests: None}

\section{References}

1 Tanaka S, Terasaki M, Kanao H et al. Current status and future perspectives of endoscopic submucosal dissection for colorectal tumors. Dig Endosc 2012; 24: $73-79$

2 Tanaka S, Terasaki M, Hayashi $N$ et al. Warning for unprincipled colorectal ESD: accurate diagnosis and reasonable treatment strategy. Dig Endosc 2013; 23: 107 -116

3 Tanaka S, Saitoh Y, Matsuda T et al. Evidence-based clinical practice guidelines for management of colorectal polyps. J Gastroenterol 2015; 50: $252-260$

4 Oka S, Tanaka S, Saito Y et al. Local recurrence after endoscopic resection for large colorectal neoplasia: a multicenter prospective study in Japan. Am J Gastroenterol 2015; 110: 697-707

5 Nakajima T, Saito $Y$, Tanaka $S$ et al. Current status of endoscopic resection strategy for large, early colorectal neoplasia in Japan. Surg Endosc 2013; 27: $3262-3270$

6 Takeuchi $Y$, Iishi H, Tanaka S et al. Factors associated with technical difficulties and adverse events of colorectal endoscopic submucosal dissection: retrospective exploratory factor analysis of a multicenter prospective cohort. Int J Colorectal Dis 2014; 29: 1275 - 1284

7 Yoshida N, Wakabayashi N, Kanemasa K et al. Endoscopic submucosal dissection for colorectal tumors: technical difficulties and rate of perforation. Endoscopy 2009; 41: 758 - 761

8 Hayashi N, Tanaka S, Nishiyama S et al. Predictors of incomplete resection and perforation associated with endoscopic submucosal dissection for colorectal tumors. Gastrointest Endosc 2014; 79: 427 - 435

9 Hawari R, Pasricha PJ. Going for the loop: a unique overtube for the difficult colonoscopy. J Clin Gastroenterol 2007; 41: 138-140

10 Tanaka S, Oka S, Chayama K. Colorectal endoscopic submucosal dissection: present status and future perspective, including its differentiation from endoscopic mucosal resection. J Gastroenterol 2008; 43: $641-651$

11 Matsumoto A, Tanaka S, Oba S et al. Outcome of endoscopic submucosal dissec- tion for colorectal tumors accompanied by fibrosis. Scand J Gastroenterol 2010; 45: 1329-1337

12 Pasha SF, Harrison ME, Das A et al. Utility of double-balloon colonoscopy for completion of colon examination after incomplete colonoscopy with conventional colonoscope. Gastrointest Endosc 2007; 65: $848-$ 853

13 Teshima CW, Aktas H, Haringsma J et al. Single-balloon-assisted colonoscopy in patients with previously failed colonoscopy. Gastrointest Endosc 2010; 71: 1319-1323

14 Keswani RN. Single-balloon colonoscopy versus repeat standard colonoscopy for previous incomplete colonoscopy: a randomized, controlled trial. Gastrointest Endosc 2011; 73: 507 - 512

15 Ohya T, Ohata K, Sumiyama K et al. Balloon overtube- guided colorectal endoscopic submucosal dissection. World J Gastroenterol 2009; 15: $6086-6090$ 